\title{
COBERTURA DA CULTURA DA SOJA PELA CALDA FUNGICIDA EM FUNÇÃO DE PONTAS DE PULVERIZAÇÃO E VOLUMES DE APLICAÇÃO' ${ }^{1}$
}

\section{COVERAGE OF SOYBEAN CROP BY SPRAYING LIQUID DUE NOZZLES AND SPRAYING VOLUME}

\author{
Rodrigo Alberto Alandia ROMÁN ${ }^{2}$ \\ Jorge Wilson CORTEZ ${ }^{3}$ \\ Marcelo da Costa FERREIRA ${ }^{4}$ \\ José Rodolfo Guimarães di OLIVEIRA ${ }^{5}$
}

\begin{abstract}
RESUMO
O objetivo do presente trabalho foi avaliar a cobertura da cultura da soja na aplicação de fungicida em função de pontas de pulverização (ponta de jato cônico e duas pontas de jato plano anexado a um corpo de bico DUO) e três volumes de calda $\left(100,150\right.$ e $\left.200 \mathrm{dm}^{3} \mathrm{ha}^{-1}\right)$. O experimento foi realizado em Janeiro de 2008 em área da Fazenda de Ensino, Pesquisa e Extensão da UNESP campus de Jaboticabal. Foi utilizada uma área de $288 \mathrm{~m}^{2}$, com o delineamento experimental em blocos ao acaso em esquema fatorial $2 \times 3 \mathrm{com} 4$ repetições, totalizando de 24 parcelas experimentais de $12 \mathrm{~m}^{2}$. Para a pulverização com bicos hidráulicos foi utilizado um pulverizador costal de pressão constante mantida por $\mathrm{CO}_{2}$ comprimido com barra de $2 \mathrm{~m}$. A análise da porcentagem de cobertura foi realizada por meio da utilização de papel hidrossensível, sendo que, esse foi colocado em três posições da planta o que representa, em altura, os terços superior, médio e inferior do dossel. Para todos os terços não houve interação entre os fatores avaliados, assim como também não houve diferença estatística entre as pontas de pulverização e entre os volumes de calda. Em relação aos volumes de aplicação o de $200 \mathrm{dm}^{3} \mathrm{ha}^{-1}$ apresentou maior porcentagem de cobertura.

Palavras-chave: Tecnologia de aplicação; jato plano; jato cônico; ferrugem asiática.
\end{abstract}

\section{ABSTRACT}

The goal of this research was to evaluate two tips of spraying nozzles (hollow cone nozzle and two flat fan nozzle annexed to a nozzle body DUO) and three spray volumes (100, 150 and $\left.200 \mathrm{dm}^{3} \mathrm{ha}^{-1}\right)$, whose application was for the control of the Asian soybean rust. An area of $288 \mathrm{~m}^{2}$ was used, with a randomized blocks design in a factorial $2 \times 3$ with 4 repetitions, total of 24 experimental parcels of $12 \mathrm{~m}^{2}$. For the spraying with hydraulical nozzles a costal spray of constant pressure kept by $\mathrm{CO}_{2}$ compressed with bar of $2 \mathrm{~m}$ was used. The analysis of the covering percentage was carried through by means of the use of hidro-sensible paper, that was placed in three position of the plant what it represents, in height, the third superior, average and inferior of the canopy. For both the third no interaction between the evaluated factors, was found and meither difference statistics between the spraying tips and the volumes. In absolute values the twin flat fan nozzle DUO presented minimum difference of covering in relation to the hollow cone nozzle, and for the spray volume of $200 \mathrm{dm}^{3} \mathrm{ha}^{-1}$ presented greater covering percentage.

Key-words: Spraying technology; flat fan nozzle; hollow cone nozzles; asian soybean rust.

1 Parte da monografía de graduação em Agronomia do primeiro autor.

2 Engenheiro agrônomo, Mestrando em Agronomia - Universidade Estadual Paulista Julio de Mesquita Filho (UNESP), Jaboticabal, SP, Brasil. E-mail: rar_agronomia@yahoo.com.br.

3 Engenheiro agrônomo, Doutor em Agronomia, Professor do Colegiado de Engenharia Agrícola e Ambiental - Universidade Federal do Vale São Francisco (UNIVASF), Juazeiro - BA, Brasil. E-mail: jorge.cortez@yahoo.com.br.

4 Engenheiro agrônomo, Doutor em Agronomia, Professor do Departamento de Fitossanidade - Faculdade de Ciências Agrárias e Veterináricas (FCAV) - Universidade Estadual Paulista Julio de Mesquita Filho - Campus de Jaboticabal. Jaboticabal - SP, Brasil, CEP. 14.884900 E-mail: mdacosta@fcav.unesp.br. Autor para correspondência.

5 Engenheiro Agrônomo, Doutorando em Agronomia - Departamento de Fitossanidade - Universidade Estadual Paulista Julio de Mesquita Filho, Jaboticabal, SP, Brasil. E-mail: joserodolfoguimaraes@yahoo.com.br 
ROMÁN, R.A.A. et al. Cobertura da cultura da soja pela calda fungicida...

\section{INTRODUÇÃO}

Os produtos fitossanitários têm sido alvo de crescente preocupação, em virtude de seu potencial de risco ambiental (Barcellos et al., 1998). A aplicação correta de produtos fitossanitários, só pode ocorrer quando são empregados os princípios de tecnologia de aplicação. A tecnologia de aplicação de produtos fitossanitários é um dos mais multidisciplinares campos dentro da agricultura, uma vez que se reporta ao controle de insetos e ácaros, de plantas daninhas e de agentes patogênicos, que considera aspectos da biologia, da química, da engenharia, da ecologia, da sociologia e da economia (Ferreira, 2006).

Um dos fatores mais importantes para obter uma aplicação eficiente é a escolha correta das pontas de pulverização Estas são responsáveis pela qualidade de aplicação, visto que interferirá na vazão, cobertura do alvo e uniformidade de distribuição da calda (Bauer \& Raetano, 2004; Fernandes et al., 2007). Outra variável importante na aplicação é o volume de calda. Prática comum era se aplicar volumes superiores a $200 \mathrm{dm}^{3} \mathrm{ha}^{-1}$; Atualmente, entretanto, existe tendência de se reduzir o volume de calda, visando diminuir os custos de aplicação e aumentar a eficiência da pulverização (Silva, 1999). O uso de menor volume de calda aumenta a autonomia e a capacidade operacional dos pulverizadores em valores expressivos, podendo ser o principal componente do desempenho operacional em diversas culturas.

Grande parte dos fungicidas sistêmicos registrados apresenta movimentação no sentido da base para o ápice da folha, com mínima chance de ocorrer o contrário, e sem a possibilidade de translocação de uma folha para outra. Devido a isso a importância da escolha certa da ponta de pulverização que irá propiciar penetração eficiente e cobertura satisfatória. Dessa forma, o objetivo do presente trabalho foi avaliar a cobertura da calda de pulverização de um fungicida na cultura da soja em função de duas pontas de pulverização e três volumes de calda.

\section{MATERIAL E MÉTODOS}

O experimento foi conduzido na área experimental da Fazenda de Ensino, Pesquisa e Produção (FEPP) pertencente a UNESP de Jaboticabal - SP, localizada nas coordenadas geodésicas: latitude $21^{\circ} 14^{\prime} \mathrm{S}$ e longitude $48^{\circ} 16^{\prime} \mathrm{W}$, com altitude média de $559 \mathrm{~m}$, declividade média de $4 \%$, no período compreendido entre novembro/2007 a março/2008.

A cultura da soja foi instalada no dia 9/11/07 com a variedade Monsoy 8000 Roundap Ready com 20 sementes $\mathrm{m}^{-1}$ e população final de 444.000 plantas $\mathrm{ha}^{-1}$. Na época de aplicação a cultura da soja encontrava-se totalmente fechada entre fileiras no estágio fenológico R2, ou seja, com florescimento pleno com altura média de $65 \mathrm{~cm}$ e de 15 a 19 trifólios por planta.

O experimento foi conduzido em delineamento experimental em blocos ao acaso com 4 repetições em esquema fatorial $2 \times 3$, sendo dois tipos de ponta de pulverização (ponta de jato cônico e duas pontas de jato plano, sendo estas ultimas anexadas a um corpo de bico DUO) e três volume de calda de pulverização $(100,150$ e 200 $\left.\mathrm{dm}^{3} \mathrm{ha}^{-1}\right)$. A área de cada parcela foi de $12 \mathrm{~m}^{2} \mathrm{com}$ dimensões de $6 \times 2 \mathrm{~m}$, com área experimental de $288 \mathrm{~m}^{2}$.

O fungicida utilizado foi epoxiconazole + pyraclostrobin (Opera ${ }^{\circledR}$ ) na dosagem de $0,6 \mathrm{dm}^{3}$ $\mathrm{ha}^{-1}$. Para a aplicação do fungicida foi utilizado um pulverizador de pressão constante mantida por gás carbônico $\left(\mathrm{CO}_{2}\right)$ comprimido fabricado pela Herbicat Ltda., com barra de $2 \mathrm{~m}$ e com espaçamento entre bicos de 0,50 m, sendo 4 bicos espaçados na barra.

As pontas de pulverização utilizadas foram de energia hidráulica do tipo Teejet TXA (jato cônico vazio) com ângulo de $80^{\circ}$ e vazão de $0,757 \mathrm{dm}^{3}$ $\mathrm{min}^{-1}$ com tamanho de gotas caracterizadas como muito finas e pontas de pulverização Teejet XR anexadas a um duplicador de pontas "DUO" com a finalidade de produzir jato plano duplo com ângulo de $110^{\circ}$ e vazão de $0,379 \mathrm{dm}^{3} \mathrm{~min}^{-1}$ para cada ponta, tendo uma vazão final de $0,757 \mathrm{dm}^{3} \mathrm{~min}^{-1}$ no corpo de bico e tamanho de gotas caracterizadas como finas.

As aplicações foram realizadas no dia $16 / 01 / 08$ com início às $14 \mathrm{~h}$ e $30 \mathrm{~min}$, finalizando às $15 \mathrm{~h}$ e $30 \mathrm{~min}$ aproximadamente. A temperatura no momento da aplicação foi de 29,8 no início e 30,5 ${ }^{\circ} \mathrm{C}$ no final. A umidade relativa no início foi de $61 \%$ com variação insignificante durante a aplicação. Os ventos oscilaram entre 5 a $7 \mathrm{~km} \mathrm{~h}^{-1}$. A escolha do horário da aplicação foi em função de condições operacionais e do efeito que a umidade relativa na cultura poderia causar no papel hidrossensível em horários mais amenos, como nas primeiras horas da manhã. Ao se trabalhar com esse tipo de papel, a umidade excessiva é um fator que deve ser evitado.

A pressão de trabalho utilizada no sistema de pulverização foi de $210 \mathrm{kPa}$ sendo essa a pressão mínima recomendada pelo fabricante. Os volumes de calda foram determinados pela velocidade de trabalho, ou seja, a aplicação de 200 $\mathrm{dm}^{3} \mathrm{ha}^{-1}$ ocorreu na velocidade de $1 \mathrm{~m} \mathrm{~s}^{-1}$. Para atingir 100 e $150 \mathrm{dm}^{3} \mathrm{ha}^{-1}$ não foi possível diminuir a pressão, para esse fato, foram utilizadas velocidades de $2 \mathrm{~m} \mathrm{~s}^{-1}$ e $1,5 \mathrm{~m} \mathrm{~s}^{-1}$, respectivamente.

Para determinação da cobertura foram utilizados papéis hidrossensíveis da marca Teejet ${ }^{\circledR}$ predispostos no terço inferior, médio e superior do dossel da planta, sendo grampeados às folhas. Após a passagem do aplicador em cada parcela das quatro repetições, os papéis foram retirados e colocados em placas de Petri para assim mantê-los fora da exposição de umidade.

Após a aplicação, os papéis hidrossensíveis foram levados para o laboratório para serem digitalizados em escâner de mesa, com resolução de 300 dpi. Após a digitalização dos papéis foi utilizado o software Quant $2002^{\circledR}$ para quantificação da porcentagem de área coberta pelas gotas. A porcentagem de cobertura das gotas foi quantificada pela área manchada, subtraindo-se 
ROMÁN, R.A.A. et al. Cobertura da cultura da soja pela calda fungicida...

da área total demarcada no programa (Rodrigues, 2005).

Os dados foram analisados por meio da estatística descritiva, para permitir a visualização geral do comportamento (Vieira et al., 2002), por meio do programa Minitab ${ }^{\circledR}$. Os dados também foram analisados, utilizando-se o programa ESTAT, por meio da estatística clássica para realização do teste de $\mathrm{F}$ e comparação de médias pelo teste de Tukey a $5 \%$ de probabilidade e a análise de regressão para ambas as pontas a fim de verificar qual o modelo que melhor se ajusta aos dados.

\section{RESULTADOS E DISCUSSÃO}

$\mathrm{Na}$ Tabela 1, observam-se as medidas estatísticas descritivas para os atributos de cobertura da calda de pulverização na área experimental ocupada pela cultura da soja. Para o terço inferior da planta de soja observa-se uma pequena variação entre a média e a mediana, o que é indicativo da normalidade dos dados, esse fato também é observado nos valores de curtose (Ck) e assimetria (Cs) que se aproximam de zero, o que indica a normalidade (Tabela 1). Mas para confirmar a distribuição dos dados é necessário realizar testes específicos de normalidade, como o de ShapiroWilk (Figura 1), assim verifica-se pelo valor da probabilidade $(P)>0,05$ a distribuição simétrica dos dados, mesmo com os dados tendo altos valores de coeficiente de variação (Warrick \& Nielsen, 1980).

TABELA 1 - Medidas estatísticas descritivas dos atributos de porcentagem de cobertura da calda de pulverização do fungicida na cultura da soja.

\begin{tabular}{|c|c|c|c|}
\hline \multirow[t]{2}{*}{ Tipos } & \multicolumn{3}{|c|}{ Cobertura do fungicida (\%) } \\
\hline & Terço inferior & Terço médio & Terço superior \\
\hline Média & 3,7 & 11,4 & 21,6 \\
\hline Mediana & 3,3 & 7,7 & 18,8 \\
\hline Desvio padrão & 2,6 & 11,8 & 15,0 \\
\hline Variância & 6,7 & 138,5 & 225,0 \\
\hline C.V. & 70,6 & 103,1 & 69,4 \\
\hline Mínimo & 0,4 & 1,2 & 0,2 \\
\hline Máximo & 10,4 & 51,2 & 52,9 \\
\hline Ck & 0,4 & 4,9 & $-0,4$ \\
\hline Cs & 0,8 & 2,1 & 0,8 \\
\hline $\mathrm{P}$ & $0,10^{S}$ & $0,01^{\mathrm{A}}$ & $0,04^{A}$ \\
\hline Teste & 0,96 & 0,86 & 0,95 \\
\hline
\end{tabular}

S: distribuição simétrica pelo teste de Shapiro-Wilk; ${ }^{\text {A: }}$ distribuição assimétrica (teste de Shapiro-Wilk não significativo); C.V.: Coeficiente de Variação; Ck: Índice de Curtose; Cs: Índice de Assimetria.

No terço médio da planta de soja (Tabela 1), a aplicação de fungicida apresentou o maior valor de coeficiente de variação em relação aos demais. Dentre algumas hipóteses o "efeito guardachuva" ocasionado pelo terço superior que impede a livre passagem das gotas. Comprova-se a variação dos dados pela observação da média e da mediana, e dos valores mínimo e máximo. Os valores Ck e Cs estão distantes de zero, esses são utilizados como padrão de normalidade. Assim comprova-se a assimetria dos dados pelo teste de normalidade com valor de $\mathrm{P}<0,01$.

Nos terços superior e inferior do dossel da planta de soja (Tabela 1), houve coeficientes de variação menores em relação ao terço médio. No entanto, isso não fez com que os dados estivessem dentro da normalidade. Os valores de $\mathrm{Ck}$ e Cs mesmo próximos de zero não apresentaram normalidade, assim, estes não podem ser usados de forma conclusiva, sendo necessário o teste específico.

Em relação à distribuição de freqüência dos dados de cobertura de aplicação do fungicida no terço inferior, médio e superior da planta de soja, são apresentados na Figura 2. Para o terço inferior observa-se a curva de normalidade dos dados sem nenhum desvio, o que caracteriza como distribuição homogênea. No entanto, alguns valores acima de $6 \%$ desviam a curva à direita, caracterizando como assimetria, porém, esse fato não influenciou o teste de normalidade.

Para o terço médio pode-se observar que a curva de normalidade apresentou desvio à direita, tendo assim distribuição assimétrica. Isso pode ser comprovado pelos valores de $\mathrm{Ck}$ e Cs na Tabela 1. Valores acima de $36 \%$ de cobertura influenciaram na tendência da queda da curva para a direita (Cs) e valores de $6 \%$ de frequência afetaram o valor de Ck.

Para o terço superior observa-se uma pequena tendência de desvio à direita, influenciada pelos valores acima de $40 \%$ aproximadamente, assim apresenta distribuição assimétrica dos dados, como pode ser observado para os valores de Ck e Cs e pelo teste de normalidade (Tabela 1). 
ROMÁN, R.A.A. et al. Cobertura da cultura da soja pela calda fungicida...

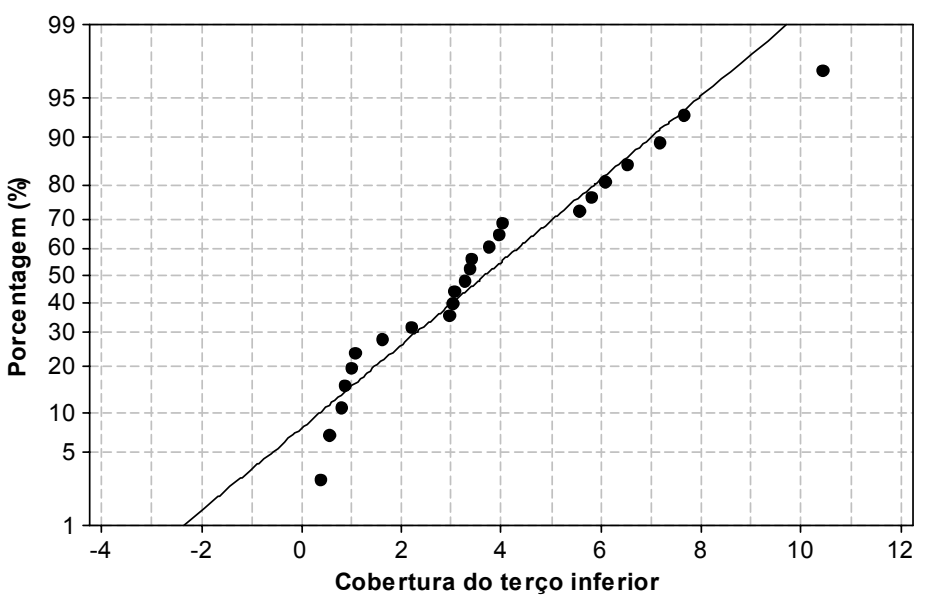

(a)

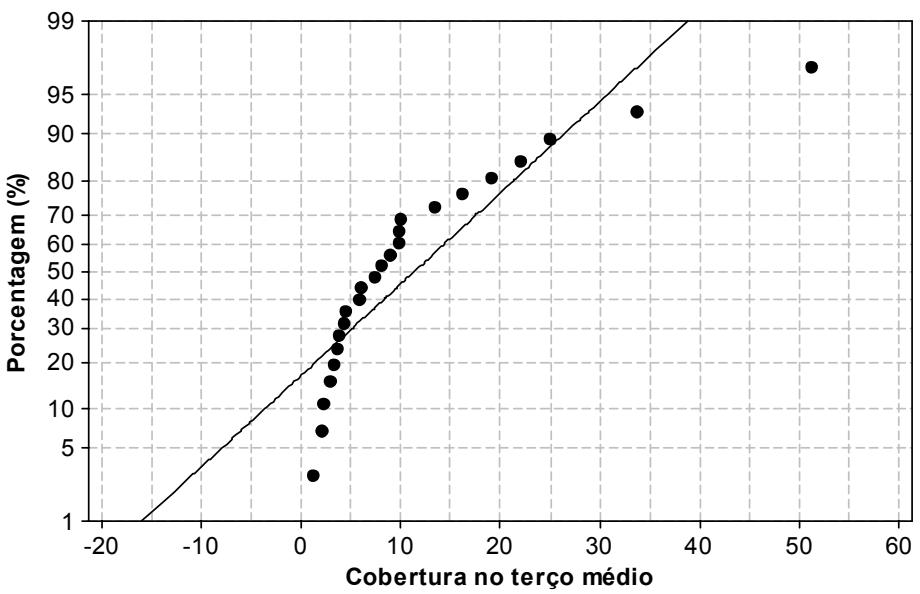

(b)

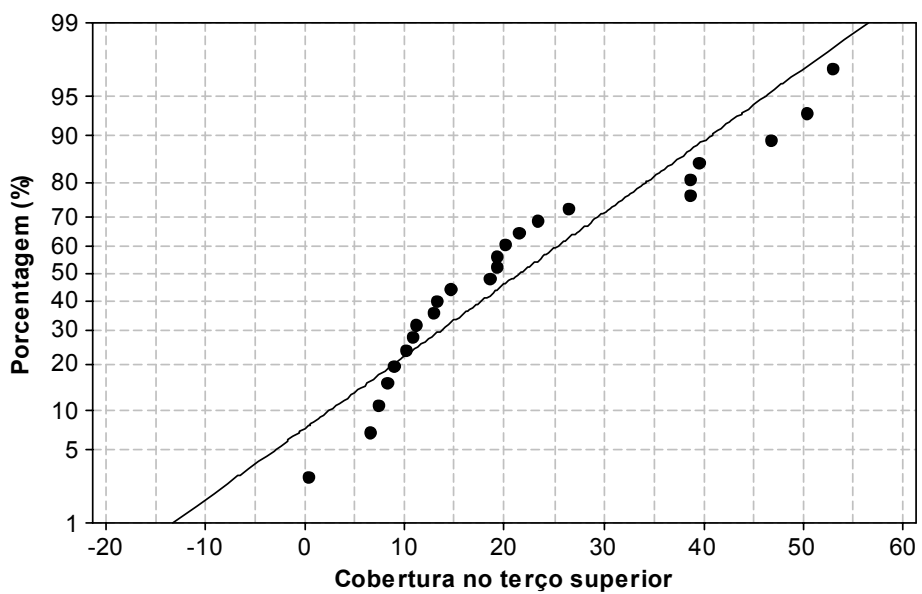

(c)

FIGURA 1 - Teste de normalidade para porcentagem de cobertura por pontas de jato plano duplo e jato cônico nos terços inferior (a), médio (b) e superior (c) da planta de soja. 
ROMÁN, R.A.A. et al. Cobertura da cultura da soja pela calda fungicida...

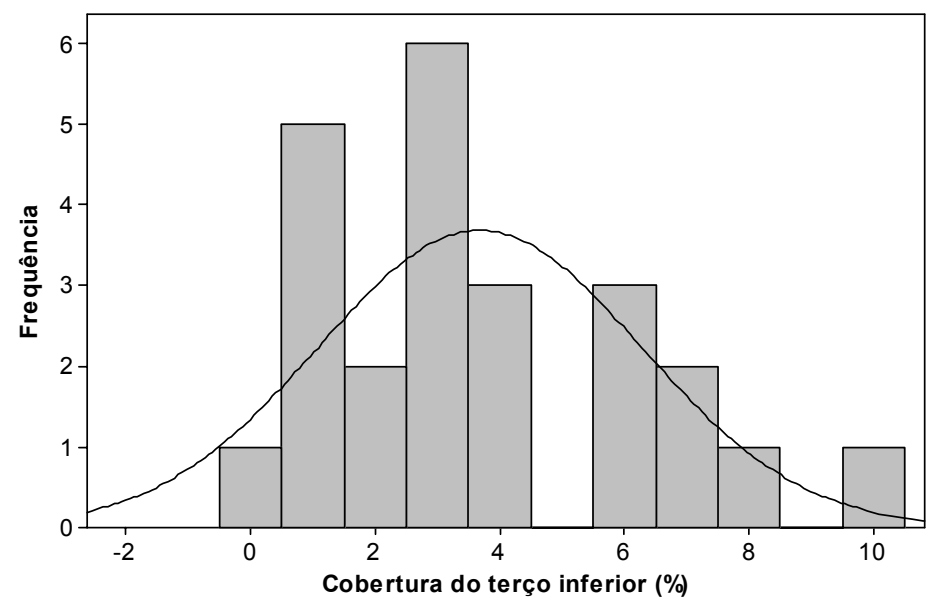

(a)

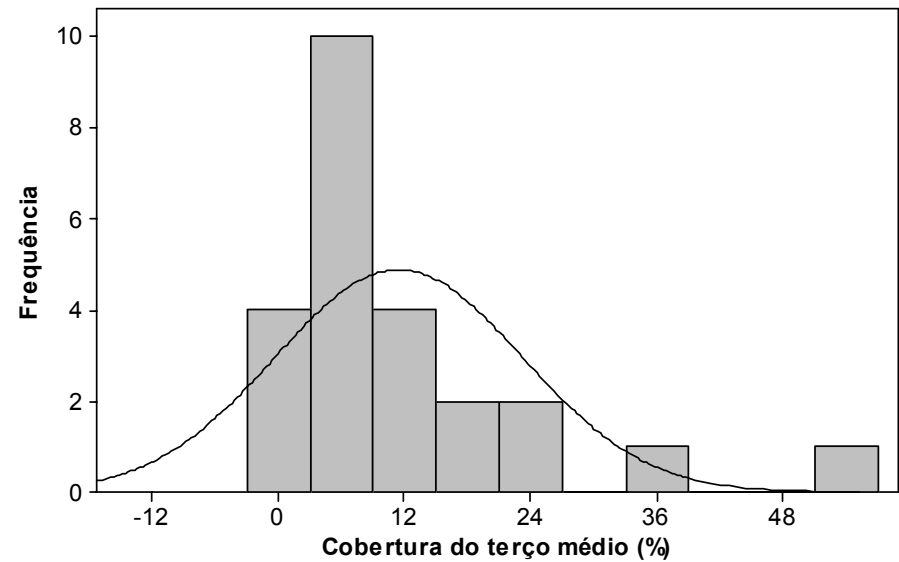

(b)

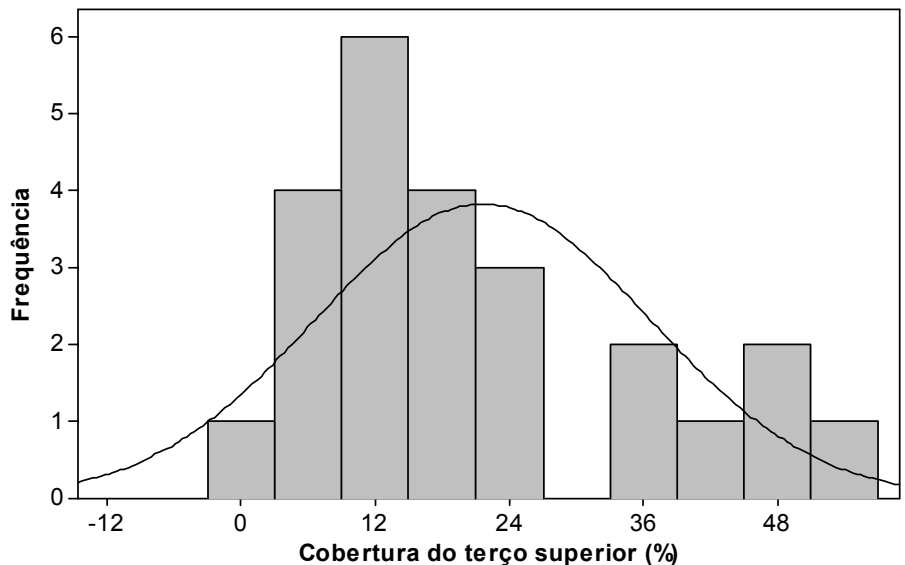

(c)

FIGURA 2 - Distribuição de freqüência com curva de normalidade da porcentagem de cobertura por pontas de jato plano duplo e jato cônico nos terços inferior (a), médio (b) e superior (c) da planta de soja. 
ROMÁN, R.A.A. et al. Cobertura da cultura da soja pela calda fungicida...

Observa-se de maneira geral pouca cobertura no terço inferior (10\%), enquanto que no terço médio e superior alguns pontos chegaram a $48 \%$ de cobertura.

No terço inferior observa-se a distribuição dos pontos ao longo da linha de probabilidade, o que caracteriza a normalidade dos dados pelo teste de Shapiro-Wilk (Figura 1)

Para o terço médio do dossel da planta de soja, os pontos encontram-se afastados da linha de probabilidade, isso pode ser observado pelo valor do $R^{2}$ de 0,86 (Tabela 1 ).

Para a porcentagem de cobertura da calda do fungicida no terço superior, observa-se que os pontos estão próximos à curva de probabilidade $\left(R^{2}\right.$ $=0,95)$, no entanto, o valor de $\mathrm{P}<0,04$ indica a assimetria dos dados. Desse modo o valor de $R^{2}$ é apenas um referencial e não pode ser tomado como medida da normalidade.

Em relação às analise de cobertura no dossel da planta de soja pode-se observar para o terço inferior que não ocorre diferença significativa para as pontas de pulverização, como também para os volumes de calda aplicados (Tabela 2), fato esse devido aos valores altos do coeficiente de variação, como proposto por Warrick \& Nielsen (1980). A explicação para isso pode-se dever ao fato de que durante a aplicação o papel hidrossensível estava aderido a folha e tenha acompanhado o movimento da planta, fazendo com que a calda aplicada tenha se concentrado na parte de baixo da folha (abaxial), resultado favorável à aplicação quando se visa o controle de doenças.

TABELA 2 - Análise de variância para os dados originais de cobertura da calda fungicida no papel hidrossensível em três posições do dossel da planta.

\begin{tabular}{lccc}
\hline & Terço inferior & Terço médio & Terço superior \\
\hline Pontas (P) & & & \\
Plano DUO & $3,8 \mathrm{a}$ & $14,4 \mathrm{a}$ & $21,1 \mathrm{a}$ \\
Cônico & $3,6 \mathrm{a}$ & $8,5 \mathrm{a}$ & $22,1 \mathrm{a}$ \\
\hline Volume de calda (V) & & & \\
100 & $2,6 \mathrm{a}$ & $7,9 \mathrm{a}$ & $15,9 \mathrm{a}$ \\
150 & $4,0 \mathrm{a}$ & $7,4 \mathrm{a}$ & $16,4 \mathrm{a}$ \\
200 & $4,5 \mathrm{a}$ & $18,8 \mathrm{a}$ & $32,5 \mathrm{a}$ \\
\hline Teste de F & & & \\
$P$ & $0,02^{\text {ns }}$ & $1,48^{\text {ns }}$ & $0,02^{\text {ns }}$ \\
V & $0,91^{\text {ns }}$ & $2,38^{\text {ns }}$ & $3,38^{\text {ns }}$ \\
Px V & $0,38^{\text {ns }}$ & $0,01^{\text {ns }}$ & $0,79^{\text {ns }}$ \\
\hline Média & 3,68 & 11,41 & 21,62 \\
\hline C.V. $(\%)$ & 79,07 & 103,93 & 66,82 \\
\hline Mers & 79,07 & nan
\end{tabular}

Médias seguidas de mesma letra minúscula na coluna não diferem pelo Teste de Tukey. NS: não significativo $(P>0,05)$;

${ }^{*}$ :significativo $(P \leq 0,05) ;{ }^{* *}$ :significativo $(P \leq 0,01), C . V$.: coeficiente de variação (\%).

Autores têm trabalhado com avaliação da cobertura do alvo e verificado resultados diversos. Santos et al. (2005), ao avaliar quatro pontas de pulverização de jato plano e dois volumes de calda, não verificaram interação significativa entre os fatores pontas de pulverização e volume de calda, o que indica independência entre estes fatores. Já Viana (2006) trabalhou com pontas de jato plano duplo e pontas de jato cônico vazio na cultura da soja e verificou diferenças significativas de cobertura entre ambas as pontas, tendo a ponta de jato plano duplo um melhor resultado. Em trabalho realizado com pontas de pulverização e espaçamento de $45 \mathrm{~cm}$ entre linhas na cultura da soja por Madalosso (2007) houve, em valores absolutos, uma melhor cobertura com a ponta de jato cônico em relação à ponta de jato plano no conector DUO, sem apresentar diferença estatística entre ambas, divergindo do trabalho de Viana (2006). Isto indica que deve haver mais fatores interagindo nos experimentos a campo que não apenas as pontas de pulverização, o que justifica mais trabalhos de pesquisas descrevendo, avaliando e quantificando com a maior quantidade possível de detalhes os parâmetros envolvidos no processo de pulverização em relação à cobertura do alvo tratado.

Pode-se observar para o terço inferior da planta que o volume de calda $200 \mathrm{dm}^{3} \mathrm{ha}^{-1}$ resultou em cobertura $42 \%$ maior que a do volume $100 \mathrm{dm}^{3}$ ha ${ }^{-1}$ e de $11 \%$ em relação ao volume $150 \mathrm{dm}^{3} \mathrm{ha}^{-1}$, ou seja, uma pequena diferença na cobertura entre os volumes de 150 e $200 \mathrm{dm}^{3} \mathrm{ha}^{-1}$.

Sendo a cobertura um fator importante no desempenho operacional dos pulverizadores a campo, a viabilidade em reduzir o volume aplicado para $150 \mathrm{dm}^{3} \mathrm{ha}^{-1}$ torna-se uma boa alternativa em relação aos custos operacionais (Tabela 2 ).

Para o terço médio da planta de soja, observa-se que a porcentagem de cobertura não foi influenciada pelos fatores avaliados. Para as pontas de pulverização ocorreu uma diferença de $40 \%$ sendo maior a cobertura na ponta leque DUO, fato esse devido à característica da ponta de pulverização apresentar diâmetro de gotas finas, com isto a penetração no dossel é maior, tanto pelo 
ROMÁN, R.A.A. et al. Cobertura da cultura da soja pela calda fungicida...

diâmetro da gota como pelo ângulo de ataque do jato plano duplo, sendo um para frente e outro para trás.

Para os volumes de calda aplicados não ocorreu diferença significativa a $5 \%$ de probabilidade pelo teste de Tukey. No entanto, observa-se diferença de $58 \%$ do volume de 200 $\mathrm{dm}^{3} \mathrm{ha}^{-1}$ em relação ao de $100 \mathrm{dm}^{3} \mathrm{ha}^{-1}$, ressalta-se que ocorre aumento de $100 \mathrm{dm}^{3}$ no volume de calda. Para o volume de $200 \mathrm{dm}^{3} \mathrm{ha}^{-1}$ em relação ao de $150 \mathrm{dm}^{3} \mathrm{ha}^{-1}$ ocorre redução de $61 \%$ na cobertura, e redução de $50 \mathrm{dm}^{3}$ na aplicação. Nesse caso, se poderia optar pela aplicação de 200 $\mathrm{dm}^{3} \mathrm{ha}^{-1}$, visto que a diferença é relevante na cobertura em relação aos outros volumes aplicados (Tabela 2). Nas condições experimentais houve baixa incidência da doença o que resulta em diferença não significativa de produtividade entre os tratamentos. Desta forma não foi possível determinar se a diferença de cobertura entre os volumes ou o teste de Tukey seria o mais adequado. Numa condição de maior incidência da doença poderia haver diferença significativa de produtividade.

Para o terço superior do dossel da planta de soja, não ocorreu diferença estatística entre os fatores avaliados. Obteve-se maior porcentagem de cobertura devido à quantidade de massa foliar, fato encontrado por Silva et al. (1997) em estudo da população de gotas na cultura do algodoeiro. Para as pontas de pulverização observa-se pequena diferença de $4,5 \%$, o que indica que o tipo de jato utilizado não influencia na porcentagem de cobertura, o que concorda com Souza (2006), que não observou diferença na cobertura entre ambas as pontas.

$\mathrm{Na}$ análise da calda aplicada observa-se diferença de $51 \%$ na cobertura entre os volumes de 200 e $100 \mathrm{dm}^{3} \mathrm{ha}^{-1}$, devido à variação de $100 \mathrm{dm}^{3}$ $\mathrm{ha}^{-1}$ na calda, esse fato é constatado na análise do terço médio. Para os volumes de 200 e $150 \mathrm{dm}^{3}$ ha ${ }^{1}$ ocorre variação de $50 \%$ na cobertura e de $50 \mathrm{dm}^{3}$ ha ${ }^{-1}$ na redução do volume aplicado (Tabela 2).

Para ambos os terços no dossel da planta, houve incremento da cobertura com o aumento do volume de calda, sem apresentar diferença estatística, resultados similares foram encontrados por Viana (2006) e Cunha et al. (2006), em que, ao estudar as pontas de pulverização e volumes de calda obtiveram incremento da cobertura com aumento da taxa de aplicação.

$\mathrm{Na}$ Tabela 3 , observa-se a análise de regressão para os volumes de calda aplicados na planta de soja versus a porcentagem de cobertura na folha para a ponta de jato plano DUO. A porcentagem de cobertura no terço inferior da planta de soja versus a porcentagem de cobertura na folha não se mostrou significativa para a regressão de grau 1 (linear) e de grau 2 (parábola), mesmo os valores do $R^{2}$ próximos a 1,00 . A falta de significância é explicada pelos altos valores do coeficiente de variação. Desse modo, optou-se por utilizar o maior valor do teste de $F$ (nesse caso 0,12 ) e construir a figura com a equação de regressão de grau 1 (linear), na Figura 3.

TABELA 3 - Análise de variância da regressão da ponta de jato plano duplo para os dados originais de cobertura pela calda fungicida.

\begin{tabular}{|c|c|c|c|}
\hline & Terço inferior & Terço médio & Terço superior \\
\hline \multicolumn{4}{|l|}{$\mathrm{R}^{2}$} \\
\hline $\mathrm{R}^{2}$ Grau 1 & 0,73 & 0,72 & 0,43 \\
\hline $\mathrm{R}^{2}$ Grau 2 & 1,00 & 1,00 & 1,00 \\
\hline \multicolumn{4}{|l|}{ Equação } \\
\hline Grau 1 & $Y=2,82+0,0063 x$ & $Y=-2,85+0,11 x$ & $Y=-2,42+0,16 x$ \\
\hline Grau 2 & $Y=0,087+0,045 x-0,0001 x^{2}$ & $Y=47,8-0,61+0,0024 x^{2}$ & $Y=127,7-1,71 x+0,0062 x^{2}$ \\
\hline C.V. (\%) & 68,34 & 112,48 & 70,34 \\
\hline
\end{tabular}

Para o terço médio da planta de soja não se observou diferença significativa entre as equações de regressão. Esse fato também é devido aos altos valores do coeficiente de variação. De maneira similar ao terço inferior optou-se por utilizar o maior valor de $F(1,00)$ para a construção da figura, nesse caso equação de regressão de grau 1. Para o terço superior da planta, não foi observada diferença significativa entre as equações. Fato esse devido ao alto valor do coeficiente de variação.

No terço inferior, médio e superior do dossel da planta de soja, a análise de regressão para calda aplicada na planta versus a porcentagem de cobertura na folha para a ponta de jato cônico não se mostrou significativa. Isso devido ao alto valor do coeficiente de variação. Em função do alto valor do coeficiente utilizou-se os maiores valores de $F$ para o terço inferior $(2,04)$, médio $(4,99)$ e superior $(3,34)$, na construção das figuras com as curvas de regressão de grau 1 (Tabela 4 ).

O produto utilizado se transloca na planta via xilema (movimento acrópeta), ou seja, a translocação ocorre das partes inferiores para as partes superiores da planta, seguindo o fluxo da transpiração (Souza, 2006). Isto indica a elevada importância em se atingir as partes mais baixas da planta, uma vez que as gotas que atingem as folhas mais expostas na parte superior do dossel não serão responsáveis pelo controle de doenças no baixeiro. 
ROMÁN, R.A.A. et al. Cobertura da cultura da soja pela calda fungicida...

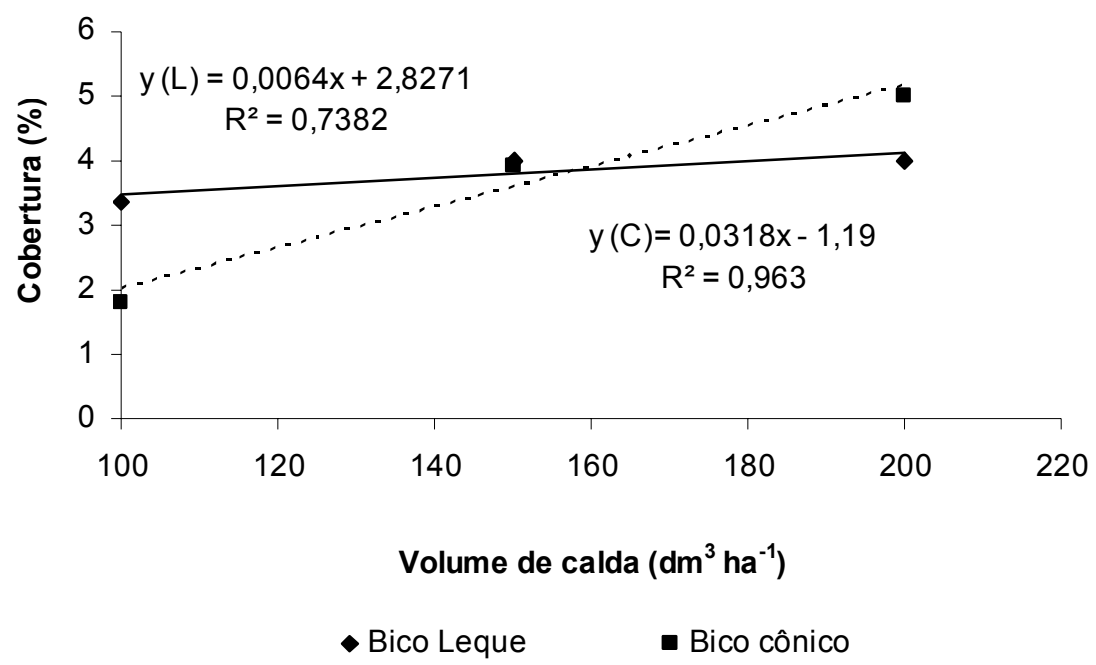

FIGURA 3 - Análise de regressão das pontas de jato plano duplo e jato cônico para a porcentagem de cobertura da calda do fungicida no terço inferior da planta de soja.

TABELA 4 - Análise de variância da regressão da ponta de jato cônico para os dados originais de cobertura pela calda fungicida.

\begin{tabular}{lccc}
\hline & Terço inferior & Terço médio & Terço superior \\
\hline$R^{2}$ & 0,96 & 0,69 & 1,00 \\
$\mathrm{R}^{2}$ Grau 1 & 1,00 & 1,00 & 1,00 \\
$\mathrm{R}^{2}$ Grau 2 & & & \\
\hline Equação & $\mathrm{Y}=-1,19+0,031 \mathrm{x}$ & $\mathrm{Y}=-7,14+0,10 \mathrm{x}$ & $\mathrm{Y}=-3,87+0,17 \mathrm{x}$ \\
Grau 1 & $\mathrm{Y}=-5,69+0,096 \mathrm{x}-0,0002 \mathrm{x}^{2}$ & $\mathrm{Y}=42,290,60+0,002 \mathrm{x}^{2}$ & $\mathrm{Y}=-4,47+0,18 \mathrm{x}-0,0003 \mathrm{x}^{2}$ \\
Grau 2 & 87,76 & 77,84 & 60,59 \\
\hline C.V. (\%) & & & \\
\hline
\end{tabular}

C.V.: coeficiente de variação (\%).

$\mathrm{Na}$ Figura 3, observa-se a equação de regressão para os volumes de calda aplicados para as pontas de pulverização do tipo leque e cônico. Desse modo, observa-se o ajuste linear para ambas as pontas de pulverização, indicando que próximo a calda de $150 \mathrm{dm}^{3} \mathrm{ha}^{-1}$, ocorre uma sobreposição das curvas, o que se pode considerar o ponto de equilíbrio entre as pontas testadas. Pode ser observado que para a ponta de pulverização de jato plano DUO. Com o acréscimo na taxa de aplicação a alteração na cobertura é praticamente desprezível. Já para o jato cônico, quando a taxa de aplicação é incrementada, observa-se uma resposta significativa no aumento da porcentagem de cobertura.

Na Figura 4, observa-se o paralelismo das retas que representam as pontas de pulverização. Assim, a ponta de jato plano DUO apresentou maior valor de cobertura em todos os volumes, mostrando-se superior à ponta de jato cônico.

$\mathrm{Na}$ Figura 5, observa-se o para a ponta de jato leque DUO, que no aumento do volume aplicado de $150 \mathrm{dm}^{3} \mathrm{ha}^{-1}$ houve redução na porcentagem de cobertura, provavelmente devido a efeitos de deposição de calda na parte abaxial da folha no momento da aplicação, evitando com que o papel hidrossensível localizado nesta região receba a calda de fungicida. No caso da ponta de jato cônico, no acréscimo da taxa de aplicação os valores da porcentagem de cobertura aumentaram. Com aumento da taxa de aplicação tende a ocorrer aumento da cobertura, fato que pode acontecer também com gotas de menores tamanhos, ao mesmo tempo, gotas com maior susceptibilidade aos efeitos de deriva, propiciando maior risco ao ambiente e ao homem.

\section{CONCLUSÃO}

Para as condições do experimento é possível concluir que:

a) As pontas de jato cônico vazio (8002) e jato plano duplo DUO (11001) foram similares quanto à porcentagem de cobertura na aplicação de fungicida;

b) Os volumes utilizados $(100,150$ e 200 $\left.\mathrm{dm}^{3} \quad \mathrm{ha}^{-1}\right)$ não diferiram estatisticamente na porcentagem de cobertura de fungicida com tendência de aumento com o incremento na taxa de aplicação.

\section{CONFLITOS DE INTERESSES}

Os autores declaram que não existe nenhum tipo de subordinação ou consultoria sobre os produtos e equipamentos utilizados neste trabalho. 
ROMÁN, R.A.A. et al. Cobertura da cultura da soja pela calda fungicida...

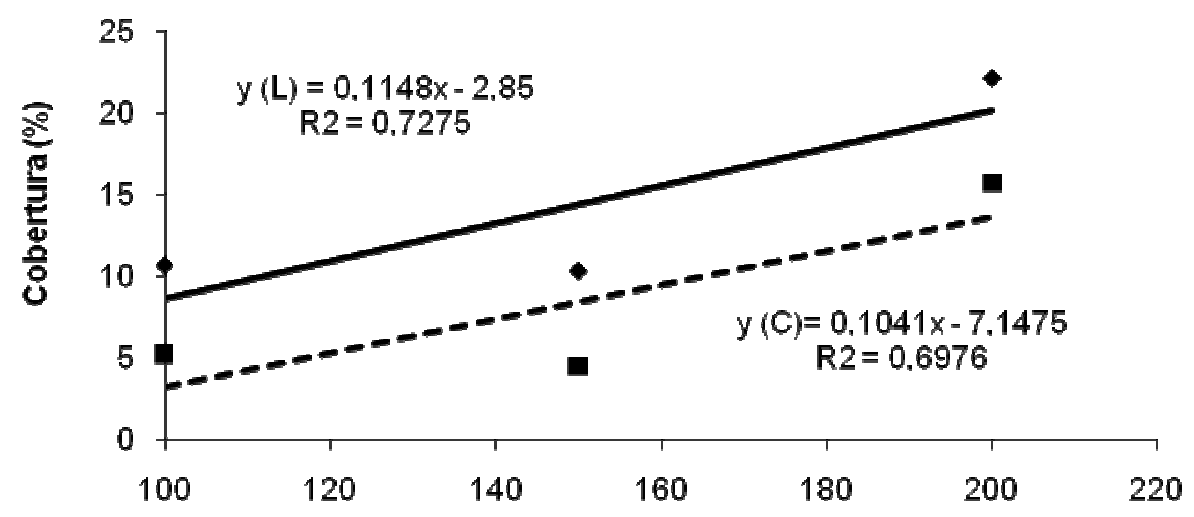

Volume de calda $\left(\mathrm{dm}^{3} \mathrm{ha}^{-1}\right)$

\section{- Bico Leque $\quad$ Bico cônico}

FIGURA 4 - Análise de regressão das pontas de jato plano duplo e jato cônico para a cobertura de fungicida no terço médio da planta de soja.

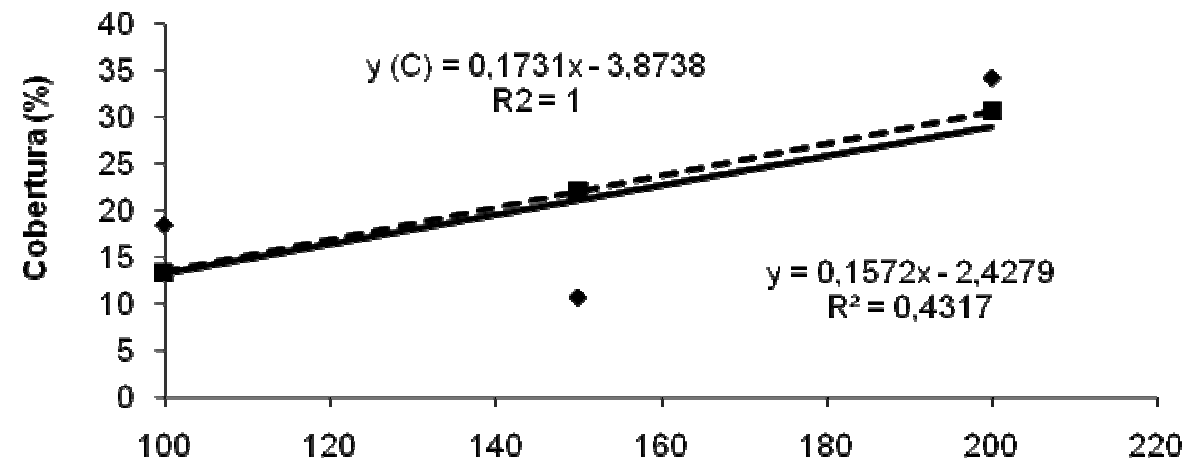

Volume de calda $\left(\mathrm{dm}^{3} \mathrm{ha}^{-1}\right)$

Bico cônico • Bico Leque

FIGURA 5 - Análise de regressão das pontas de jato plano duplo e jato cônico para a cobertura do fungicida no terço superior da planta de soja.

\section{REFERÊNCIAS}

1. BARCELLOS, L. C. et al. Estudo sobre a penetração de gotas de pulverização no dossel da cultura da soja [Glycine max (L.) Merrill. Engenharia na Agricultura, v. 6, n. 2, p. 81-94, 1998.

2. BAUER, F. C.; RAETANO, C. G. Distribuição volumétrica de calda produzidas pelas pontas pulverização XR, TP e TJ sob diferentes condições operacionais. Planta Daninha, v. 22, n. 2, p. 275-284, 2004.

3. CUNHA, J. P. A.; REIS, E. F. dos; SANTOS, R. de O. Controle químico da ferrugem asiática da soja em função de ponta de pulverização e de volume de calda. Ciência Rural, v. 36, n. 5, p. 1360-1366, 2006.

4. FERNANDES, A. P. et al. Caracterização do perfil de deposição e do diâmetro de gotas e otimização do espaçamento entre bicos na barra de pulverização. Engenharia Agrícola, v. 27, n. 3, p. 728-733, 2007.

5. FERREIRA, M. C. Tecnologia de Aplicação de Produtos Fitossanitários em cana-de-açúcar. In: SEGATO, S. V. et al. (Org.). Atualização em produção de cana-de-açúcar. Piracicaba: Prol, 2006. v. 1, p. 293-303.

6. MADALOSSO, M. G. Espaçamento entre linhas e pontas de pulverização no controle de Phakopsora pachyrhizi Sidow. 2007. 83 f. Dissertação (Mestrado em Engenharia Agrícola) - Centro de Ciências Rurais, Universidade Federal de Santa Maria, Santa Maria, 2007.

7. RODRIGUES, G. J. Critérios rastreáveis na aplicação de inseticida no controle do bicho mineiro do cafeeiro 2005. 108 f. Tese (Doutorado em Agronomia) - Universidade Federal de Viçosa, Viçosa, 2005. 
ROMÁN, R.A.A. et al. Cobertura da cultura da soja pela calda fungicida...

8. SANTOS, R. O. et al. Deposição de calda fungicida aplicada na cultura da soja, em função de ponta de pulverização e volume de calda. In: JORNADA DE PESQUISA E PÓS-GRADUAÇÂO, 1.; SEMINÁRIO DE INICIAÇÃO CIENTÍFICA, 3. 2005, Anápolis. Anais... Anápolis: UEG. v. 1. p. 1-6.

9. SILVA, O. R. R. F. da et al. Avaliação do depósito de gotas através da pulverização eletrostática e da convencional sobre a cultura do algodoeiro. Revista Brasileira de Engenharia Agrícola Ambiental, v. 1, n. 1, p. 101-105, 1997.

10. SILVA, O. C. Tecnologia de aplicação de fungicidas. In: CANTERI, M. G. et al. (Ed.). Principais doenças fúngicas do feijoeiro. Ponta Grossa: UEPG, 1999. p.127-137.

11. SOUZA, G. V. R. de. Ponta de pulverização e pressão de trabalho na aplicação de tebuconazole para o controle da ferrugem da soja. 2006. 49 f. Dissertação (Mestrado em Fitotecnia) - Universidade Federal de Viçosa, Viçosa, 2006.

12. VIANA, R. G. Avaliação de pontas de pulverização sob diferentes condições operacionais. 2006. 42 f. Dissertação (Mestrado em Fitotecnia) - Universidade Federal de Viçosa, Viçosa, 2006.

13. VIEIRA, S. R. et al. Handbook for geoestatical analysis of variability in soil and climate data. In: ALVAREZ V. V. H. et al. (Ed.). Tópicos em ciência do solo. Viçosa, MG: Sociedade Brasileira de Ciência do Solo, 2002. v. 2, p. 1-45.

14. WARRICK, A. W.; NIELSEN, D. R. Spatial variability of soil physical properties in the field. In: HILLEL, D. (Ed.). Applications of soil physics. New York: Academic Press, 1980. p. 319-344.

Recebido em 01/09/2008

Aceito em 28/04/2009 